\title{
A Review of Wireless Power Transfer for Electric Vehicles: Prospects to Enhance Sustainable Mobility
}

\author{
Zicheng Bi ${ }^{\text {a, }}$, Tianze Kan ${ }^{\text {b,c, }}$, Chunting Chris Mi ${ }^{b}$, Yiming Zhang ${ }^{d}$, Zhengming Zhao ${ }^{d}$, \\ Gregory A. Keoleian ${ }^{\mathrm{a}, *}$ \\ ${ }^{\text {a }}$ Center for Sustainable Systems, School of Natural Resources and Environment, University of \\ Michigan, 440 Church St., Ann Arbor, MI 48109, United States \\ ${ }^{\mathrm{b}}$ Department of Electrical and Computer Engineering, San Diego State University, 5500 \\ Campanile Dr., San Diego, CA 92182, United States \\ ${ }^{\mathrm{c}}$ Department of Electrical and Computer Engineering, University of California at San Diego, \\ 9500 Gilman Dr., La Jolla, CA 92093, United States \\ ${ }^{\mathrm{d}}$ Department of Electrical Engineering, Tsinghua University, 30 Shuangqing Rd., Beijing \\ 100084, China
}

Submitted to Applied Energy

February 2016

First Revision: May 2016

Second Revision: June 2016

${ }^{\dagger}$ Equal contribution from these authors.

* Corresponding author. Tel.: +1 7347643194.

Email address: gregak@umich.edu (G.A. Keoleian). 


\begin{abstract}
Wireless power transfer (WPT), which transmits power by an electromagnetic field across an intervening space, provides the prospect of new opportunities for electric vehicles (EVs) to enhance sustainable mobility. This review article evaluates WPT technology for EV applications from both technical and sustainability perspectives. The objectives of this review include: (1) to present the state-of-the-art technical progress and research bottlenecks in WPT development and applications in the transportation sector; (2) to characterize the demonstrations of the real-world deployment of WPT EV systems; and (3) to evaluate the sustainable performance and identify challenges and opportunities for improvement. From the technical perspective, progress on coil design, compensation topologies, and power electronics converters and control methods are reviewed with a focus on system performance. From the sustainability perspective, performance is defined in terms of energy, environmental, and economic metrics, and policy drivers and issues of health and safety are also examined.
\end{abstract}

Keywords: Wireless power transfer; Sustainability; Electric vehicle; Wireless charging; Environmental impact; Energy efficiency 


\section{Introduction}

A century ago, Nicola Tesla conducted experiments to transfer power wirelessly [1,2]. In recent decades, wireless power transfer (WPT) has been an area of intensive research to facilitate the penetration of electric products into our lives. Typical examples include wireless charging cell phones, electric vehicles (EVs), implanted medical devices, robots, and home electronic appliances. The power is typically transferred via an electromagnetic field (EMF). The widespread applications and increasing demand for WPT stems from its inherent convenience and possibility of seamless operation without charging downtime that are otherwise two major problems for wired chargers. Based on the working principles, WPT can be categorized as (1) electromagnetic radiation (microwave or laser) WPT that is applicable for long-distance power transmission, such as transmission between solar power satellites and the earth, (2) electric induction/coupling WPT (also known as capacitive coupling WPT) that is for near field transmission, and (3) magnetic coupling WPT (inductive or resonant) that is also for near field transmission but does much less harm to the human body than electric induction/coupling WPT due to the intensity of the electric field [3, 4]. Extensive work [3, 5-8] has been done on magnetic coupling WPT for EV charging applications, which is the focus of this review. In terms of working modes, WPT can be classified as either (1) static or stationary WPT: charge while the vehicle is not in motion; or (2) dynamic WPT: charge while the vehicle is moving along the WPT-enabled roadway.

WPT for EVs has the potential to overcome the drawbacks of wired chargers and eliminate some hurdles towards vehicle electrification and sustainable mobility [9]. Aside from its convenience compared to wired chargers, WPT can enable significant downsizing of the onboard EV battery. Take the stationary WPT for electric transit buses as an example where the onboard rechargeable battery can be downsized by at least two thirds $[10,11]$ due to the frequent "opportunity charges" while loading and unloading passengers at bus stations during bus operation. Attributable to these charges en route, it is reasonable to carry a much smaller onboard battery while still fulfilling the vehicle route requirements. This results in a tremendous vehicle weight reduction given that the battery pack can comprise about a quarter of the weight of an allelectric transit bus for sustaining day-long operation [12]. Battery downsizing has significant implications for lightweighting the vehicle and improving the fuel economy [10]. In the scenario of dynamic WPT for passenger cars on major roadways, ubiquitous charging infrastructure would theoretically allow EVs to have unconstrained range and a minimal capacity of onboard battery [13]. Nevertheless, WPT for EVs poses additional sustainability trade-offs and concerns that have stimulated discussion in academia and industry. The trade-off is on the burden of largescale WPT infrastructure deployment versus the benefits of battery downsizing and fuel economy improvement. The concern is on the technical and economic feasibility of dynamic WPT and the decrease in charging performance when the vehicle is moving at high speeds.

This review article summarizes both the most up-to-date technical advances of WPT technology for EV applications and the state of sustainability assessments of WPT EV systems. 
It aims to identify current research highlights, gaps, challenges, and opportunities of WPT technology for EVs from both the technical and sustainability perspectives. The article first introduces the fundamental theory of WPT and reviews the technical advances and challenges for both stationary and dynamic WPT. The second part highlights selected case studies of WPT applications. The third part summarizes the discussions on the sustainability, safety, and social implications of WPT technology, identifies challenges and opportunities for improving performance, and provides prospects to enhance sustainable mobility.

\section{State-of-the-art research and technology development}

Figure 1 shows a non-ionizing radiative wireless charging system for EVs through nearfield magnetic coupling. The alternating current (AC) utility power first goes through the electromagnetic interface (EMI) stage, and then gets rectified and boosted to direct current (DC) power with a power factor of nearly 1.0 (0.95 to 0.98 in most cases), which is similar to a conductive charging system [14]. The voltage of the DC power is decreased by the BUCK stage. The BUCK stage can tune its output voltage to range from 0.03 to 0.97 of its input voltage, which achieves "soft" start/stop of the charger and continuous tuning of its output power. Here, the buck stage is optional since alternatively a pre-charge circuit, which is composed of two contactor relays and one resistor, is able to help achieve "soft" start of the charger and a phaseshift method can be used in the inverter stage to ensure the low power operation and "soft" stop of the charger. This combination of a pre-charge circuit and phase-shift method instead of a buck stage may reduce the system efficiency, but it will lower the total cost and volume of a wireless charging system. In the inverter stage, the DC power is converted to high frequency AC power, which then resonates in the primary compensation network and the primary coil, with the resonant frequency adjusted to the switching frequency of the inverter. The secondary coil receives the high frequency AC power wirelessly through the mutual inductance between the primary and secondary coils. The secondary compensation network, together with the secondary coil, is required to be tuned to have the same resonant frequency in order to maximize the transfer efficiency. The high frequency AC power is then rectified to DC power through the rectifier stage and filtered by the filter network. Finally, the DC power is available to charge the battery pack. 


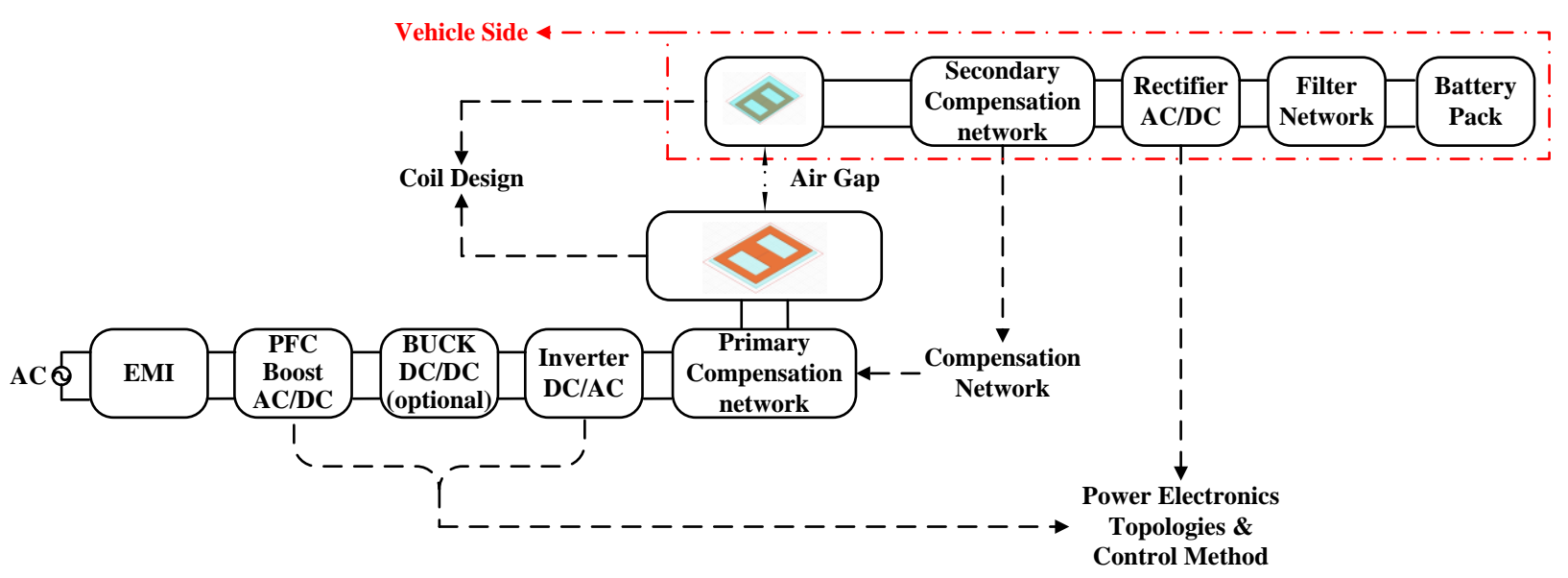

Figure 1. A non-ionizing radiative wireless charging system for electric vehicles. $\mathrm{AC}=$ alternating current; EMI = electromagnetic interface; $\mathrm{PFC}=$ power factor correction; $\mathrm{DC}=$ direct current.

Research into wireless charging systems is mainly focused on three areas: (1) coil design; (2) compensation topologies; and (3) power electronics converters and control methods.

\subsection{Coil design}

The coil is one of the most significant parts in a wireless charging system, for it converts energy between its electric form and its magnetic form, making WPT possible, while also determining the amount of power transferred and the system efficiency. In the literature, a coil system is generally classified as either a four-coil or a two-coil system. A four-coil system [1517] offers the advantage of two degrees of freedom that the source coil can be mounted and coupled with the sending coil to adjust the system input impedance, and the load coil can be mounted and coupled with the receiving coil to adjust the equivalent load resistance seen from the receiving coil to match the load condition. A four-coil system is suitable for mid-range applications while a two-coil system gives better performance in short-range applications [18]. In [18], applications are considered short-range or mid-range based on whether the transmission distance is smaller or larger than the coil dimension. In EV applications, the transmission distance, also known as air gap, ranges typically from $100 \mathrm{~mm}$ to $300 \mathrm{~mm} \mathrm{[19],} \mathrm{and} \mathrm{the} \mathrm{coil}$ dimension is always larger than the transmission distance. Therefore, a two-coil system is preferable and will be reviewed in detail in this article. In addition, ferrite bars or plates are always employed in coil systems to guide magnetic flux and provide magnetic shielding. Aluminum shields are often built into a coil system and serve as magnetic shields. Wireless charging systems for EVs are divided into stationary and dynamic charging systems, with each type having different coil designs.

2.1.1 Coil design for stationary charging systems 


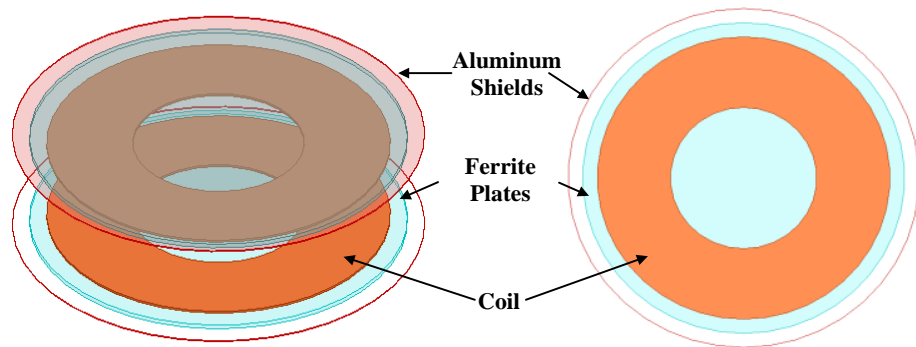

(a)

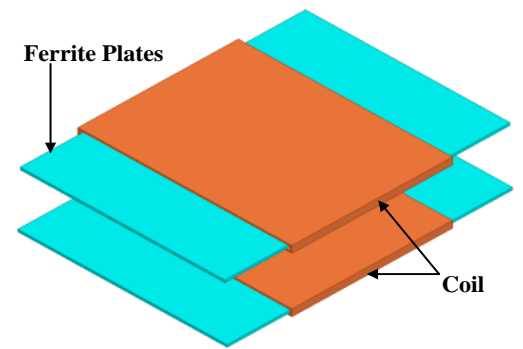

(b)

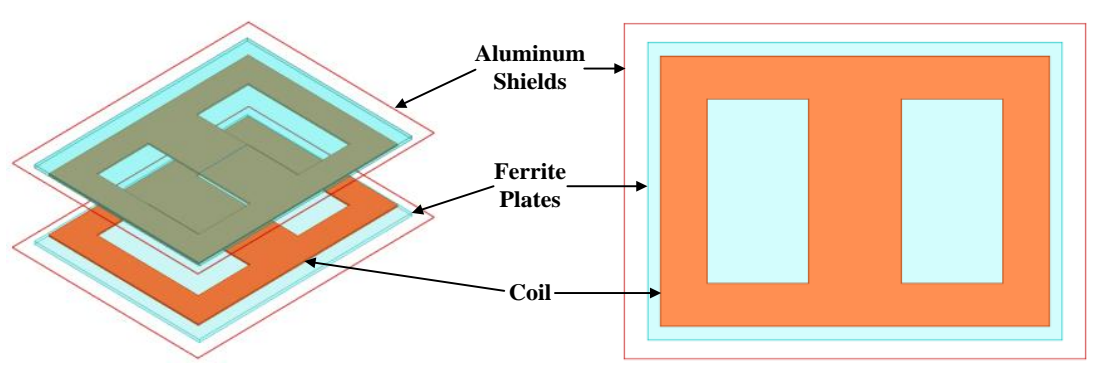

(c) 
Figure 2. Coil systems: (a) Circular structure (b) Solenoid structure (c) Bipolar structure.

A more advanced coil design can be found in [26]. Figure 3 shows the proposed coil structure, where intermediate $L_{\text {int }}$ is embedded into the primary coil structure $L_{1} . L_{\text {int }}$ and its resonant capacitor form a passive resonant circuit, which is energized through coupling effect between $L_{\text {int }}$ and $L_{1}$. Since there is also a coupling effect between $L_{\text {int }}$ and the secondary coil structure $L_{2}$, the coupling of the whole coil system is improved. This design claims a higher efficiency than that of a circular coil system, though in terms of tuning it is more complicated.

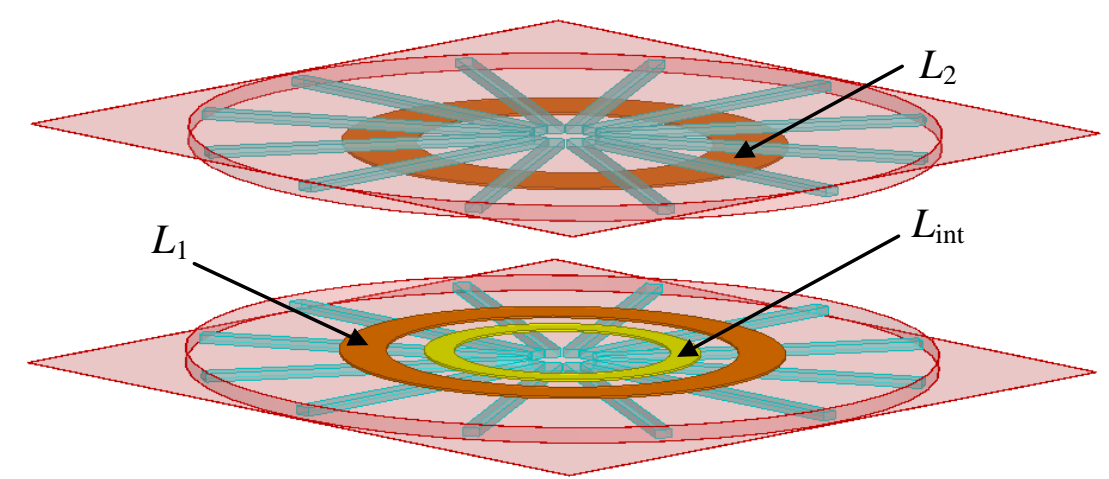

Figure 3. Advanced coil structure. $L_{\text {int }}=$ intermediate structure; $L_{1}=$ primary coil structure; $L_{2}=$ secondary coil structure. [26]

2.1.2 Coil design for dynamic charging systems

Dynamic charging systems can help further reduce the size of the battery pack on a vehicle and offer the vehicle more convenience and flexibility. There are two kinds of coil structure used in dynamic charging systems for EVs. The major difference between the two coil structures is on the primary coil side: one uses the single-coil design (a long track loop that can still be considered as a coil because of its working principle) [27-29] shown in Figure 4 (a) and the other employs the segmented-coil design $[6,9,30,31]$ shown in Figure 4 (b).

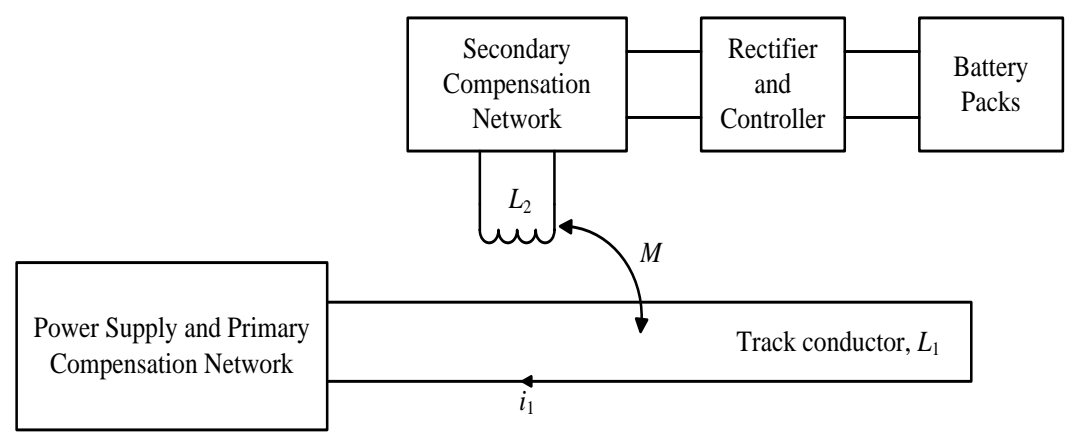

(a) 


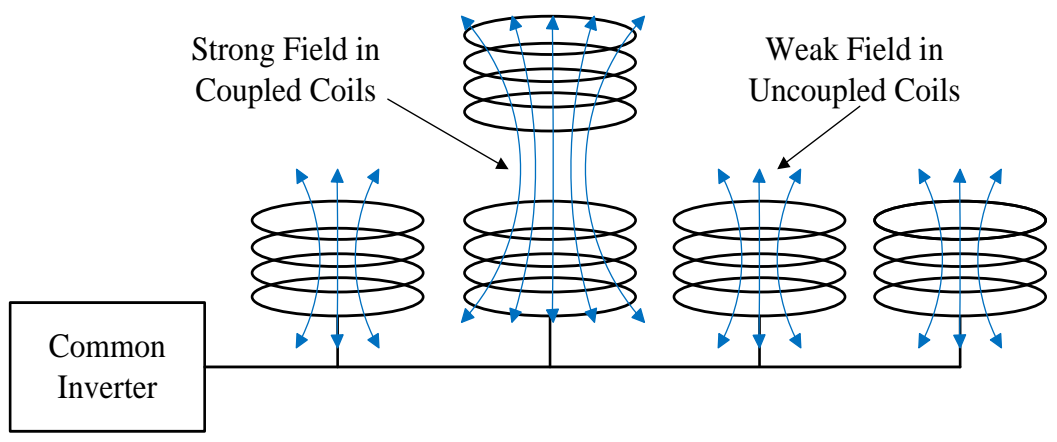

(b)

Figure 4. Typical coil configurations for dynamic charging systems with (a) single-coil design for primary coil and (b) segmented-coil design for primary coil. $L_{1}=$ track conductor; $L_{2}=$ receiver coils; $M=$ mutual inductance between $L_{1}$ and $L_{2} ; i_{1}=$ the (excitation) current in the primary coil. [27, 30]

In a single-coil design for the primary coil, the drawback is that when the track conductor $\left(L_{1}\right)$ is not covered by the receiver coils $\left(L_{2}\right)$, it not only generates a redundant EMF, but also results in low efficiency of the whole system. To overcome this problem, researchers from Korea Advanced Institute of Science and Technology (KAIST) proposed a new cross-segmented power supply rail, in which two pairs of power cables were wound in I-type ferrites. By controlling the current direction in the power cables, they were able to power the rails on and off selectively. In addition, the power cables were wound in twisted pairs, which greatly reduced EMF issues [28]. In order to further improve system performance, they introduced a new track rail wound in ultraslim S-type ferrite cores. The minimal amount of power cables and ferrite cores were employed, reducing the total construction cost. This design had better misalignment tolerance and lower EMF than the rail wound in the I-type cores [29]. Researchers from North Carolina State University (NCSU) used a segmented-coil design for the primary coil and employed the reflected reactance from the secondary coil to self-increase the magnetic field strength in the coupled section between the transmitter and the receiver [30]. As shown in Figure 4 (b), the magnetic field is strong in the coupled coils and weak in the uncoupled coils. This not only simplifies the control method, but also improves the system efficiency. However, speed-dependent pulsating power is common in this coil design, resulting from the moving vehicle passing over a sequence of coils that causes the alignment and straddling of magnetic fields. The power pulsation can shorten the battery service life and is detrimental to the power grid. Researchers from Oak Ridge National Laboratory (ORNL) had an innovative solution that utilized electrochemical capacitors to smooth power pulsation on both the grid side and vehicle side. They demonstrated that the active parallel combination of lithium-capacitor ( $\mathrm{LiC}$ ) energy storage and the grid supply resulted in very uniform power draw from the grid, where active parallel means that a highpower, bidirectional controllable power flow, DC-DC converter interfaces the LiCs to the DC input of the high-frequency inverter. Furthermore, they installed passive parallel LiCs in vehicle and successfully smoothed the battery currents [31]. 


\subsection{Compensation topologies}

A two-coil system is a loosely coupled transformer [4] with leakage inductances that require the use of compensation topologies. On the primary (or transmitter) side the compensation topology is employed to minimize the VA rating of the power supply and achieve zero phase angle (ZPA), which means there is no need for the power supply to provide reactive power so the apparent power equals the real power. On the secondary (or receiver) side the compensation topology tunes the circuit to have the same resonant frequency as the transmitter side to maximize power transfer [32]. In addition, compensation topologies help soft switching of power transistors and reduce switching losses. Another benefit of compensation topologies is to achieve constant current or constant voltage charging, which means when the root mean square value of the input voltage is fixed, then either output DC current or DC voltage is fixed. Four basic compensation topologies, named SS, SP, PS, and PP, are presented in Figure 5. Here, "S" or "P" stands for series or parallel, indicating how the compensation capacitors are connected to the coils. The first letter represents the transmitter side and the second letter represents the receiver side. First harmonic analysis (FHA) is a basic analysis method used to analyze the circuits and $v_{a c}$ is the fundamental component of the input voltage of the inverter stage. Although the battery is a voltage-source-based load and the battery voltage varies with its state of charge, the battery voltage value needs to be fixed as a criterion for designing a wireless charging system at the rated power level. Therefore, the battery is considered as a resistive load and $R_{\text {eq }}$ is the equivalent resistance at the input side of the rectifier stage.

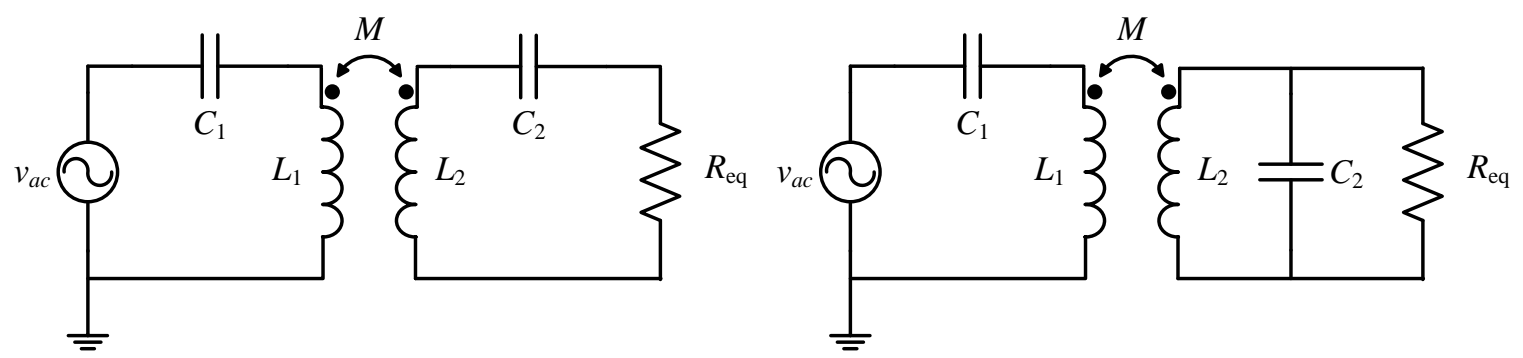

(a)

(b)

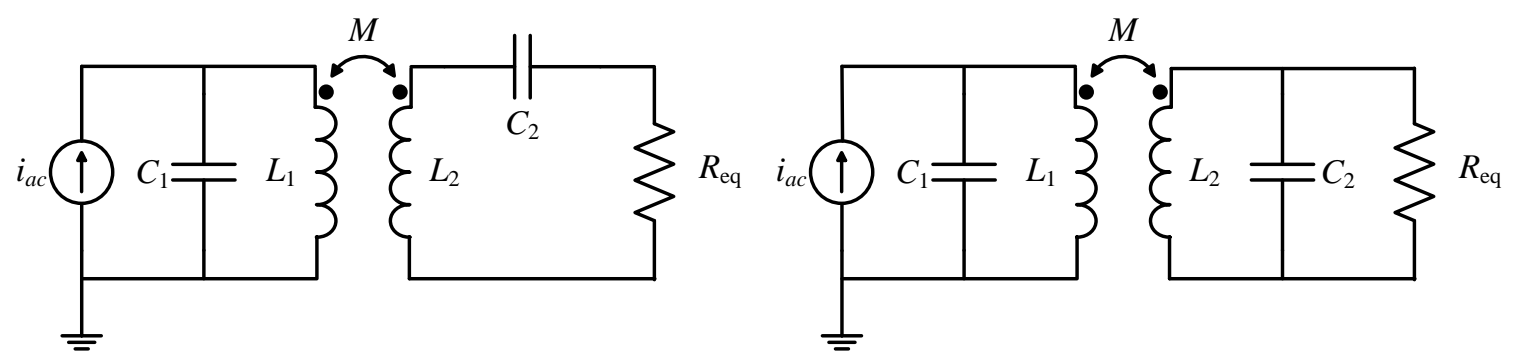

(c)

(d) 

$L_{1}, L_{2}=$ coils; $v_{a c}=$ alternating voltage; $i_{a c}=$ alternating current $M=$ mutual inductance between the primary and secondary coils; $R_{\text {eq }}=$ equivalent resistance.

The four basic compensation topologies were analyzed in [33-36]. SS and SP are more economically suitable for high power transmission [36]. Wang et al. [33] introduced the bifurcation phenomenon and studied the four basic compensation topologies. They demonstrated that the primary capacitance $C_{1}$ in PS and PP compensation topologies depends on the load condition while in SS and SP compensation topologies it does not. Therefore, SS and SP compensation topologies are more suitable for variable load conditions since the resonance is guaranteed.

A more recent compensation topology, known as the double-sided $L C C$ compensation topology, was proposed by researchers from the University of Michigan, Dearborn (UMDearborn) [37]. As shown in Figure 6, the compensated coil $L_{f 1}$ resonates with the capacitor $C_{f 1}$; therefore, $i_{1}$ is a constant current once $v_{a c}$ is fixed and the induced voltage source $j \omega M i_{1}$ is constant ( $\omega$ is angular frequency in radians per second). On the receiver side, $L_{2}$ and $C_{2}$ are combined together to resonate with $C_{f 2}$ and as a result, the resonant frequency is independent of the load condition and coupling coefficient. The output current is constant, which is desirable for battery charging. Due to the symmetry of the double-sided compensation topology, $L_{f 2}$ resonates with $C_{f 2}$ while $L_{1}$ and $C_{1}$ are combined to resonate with $C_{f 1}$. The expressions for output current $i_{f 2}$, output power $P$, and coupling coefficient $k$ are given in Eq. (1), Eq. (2), and Eq. (3) below, respectively:

$$
\begin{aligned}
& i_{f 2}=\frac{k \sqrt{L_{1} L_{2}} v_{a c}}{j \omega L_{f 1} L_{f 2}}=\frac{2 \sqrt{2}}{\pi} \cdot \frac{k \sqrt{L_{1} L_{2}} V_{i n}}{\omega L_{f 1} L_{f 2}} \angle-90^{\circ} \\
& P=\frac{8 k \sqrt{L_{1} L_{2}} V_{\text {in }} V_{\text {out }}}{\pi^{2} \omega L_{f 1} L_{f 2}} \\
& k=\frac{M}{\sqrt{L_{1} L_{2}}}
\end{aligned}
$$

where $V_{\text {in }}$ is the input voltage of the inverter stage, $V_{\text {out }}$ is the battery pack voltage, and $M$ is mutual inductance of primary $\left(L_{1}\right)$ and secondary $\left(L_{2}\right)$ coils. As can be seen from Eq. (1) and Eq. (2), the output current is constant when $V_{\text {in }}$ is fixed and the output power is linearly related to the coupling coefficient $k$ in the two-coil system. However, the double-sided LCC compensation topology introduces two space-consuming compensated coils compared to the SS compensation topology. In order to solve this problem, $[38,39]$ first integrated the compensated coils into the two-coil system. Their compact system delivered $6.0 \mathrm{~kW}$ power with over 95\% DC-DC efficiency at an air gap of $150 \mathrm{~mm}$. However, redundant coupling effects appeared after their 
integration. To simplify the analysis and design, Kan et al. [40] proposed a new integration method which not only kept the compactness and high transfer efficiency, but also eliminated or minimized the redundant coupling effects caused by integration to a negligible level.
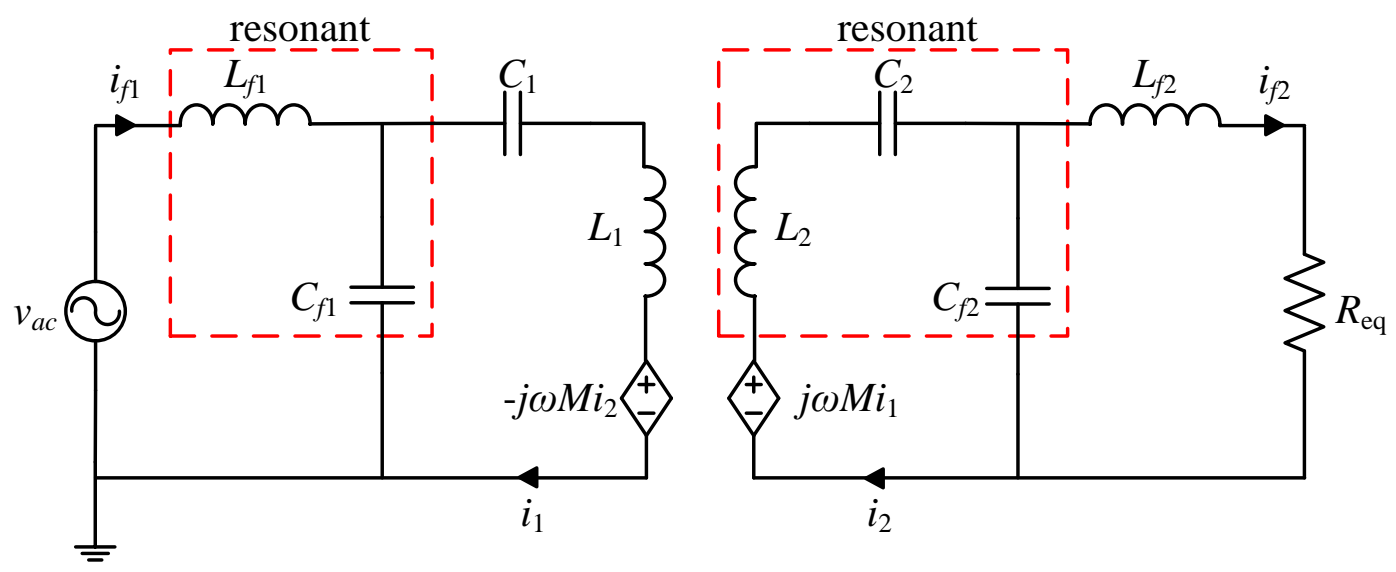

Figure 6. A double-sided $L C C$ compensation topology. $v_{a c}=$ alternating voltage; $L_{1}, L_{2}, L_{f 1}, L_{f 2}=$ coils; $C_{1}, C_{2}, C_{f 1}, C_{f 2}=$ capacitors; $i_{1}, i_{2}, i_{f 1}, i_{f 2}=$ current; $R_{\mathrm{eq}}=$ equivalent resistance; $j \omega M i_{1}=$ induced voltage source; $-j \omega M i_{2}=$ the voltage induced by the secondary coil. [40]

\subsection{Power electronics converters and control methods}

On the transmitter side, power electronics converters transform $60 \mathrm{~Hz}$ utility AC power into high frequency $\mathrm{AC}$ power on the desired power level. There are two methods to achieve the conversion: (1) The dominant method is the indirect two-stage power conversion, with the $60 \mathrm{~Hz}$ utility power first rectified into DC power, then inverted into high frequency AC power using a full-bridge inverter; (2) The other less commonly used method is the direct power conversion from $60 \mathrm{~Hz}$ utility $\mathrm{AC}$ power to high frequency $\mathrm{AC}$ power utilizing $\mathrm{AC} / \mathrm{AC}$ converters. On the receiver side, the high frequency AC power is rectified to DC power using a full-bridge rectifier in order to charge battery packs. The resonant frequency is set by the compensation networks and realized by the inverter. The resonant frequency or the switching frequency of the inverter ranges from $20 \mathrm{kHz}$ to $100 \mathrm{kHz}$ in wireless charging systems for EVs. However, with the advent of new silicon carbide MOSFETs, the resonant frequency can be as high as $1 \mathrm{MHz}$ [41]. Higher frequencies make the wireless charging system more compact, but other issues introduced by high frequency AC, such as EMF emissions, need to be further studied.

The control method of a wireless charging system is an important topic closely related to power electronics converters. Many control methods have been developed in stationary charging systems [21, 42-45] and dynamic charging systems [46, 47]. In the stationary charging applications, the control methods are designed to achieve high system efficiency, desired outputs, and bidirectional power transfer between grid and battery packs. In [21], the authors proposed a new dual side control method and established a $5.0 \mathrm{~kW}$ wireless charging system with over $90 \%$ 

system and controlled the switching frequency of the inverter on the transmitter side to achieve the desired output voltage. Researchers from ORNL employed a semi-bridgeless active rectifier on the receiver side and proposed a control strategy to phase-shift tune the switches in order to adjust the output voltage. Furthermore, they pointed out that the proposed control method was suitable for multiple secondary coil applications [43]. Control methods to realize bidirectional power flow were given in $[44,45]$. Bidirectional WPT for EVs can achieve interactions between mass EVs and the power grid. EVs can be regarded as controllable power source and load at the same time, which is beneficial for the power balance of the grid. [48] presented an optimized phase-shift modulation strategy to minimize the coil losses of a series-series WPT system. In dynamic charging applications, control methods were studied for fast turn-on in the tracking circuit without overshoot in a no-load condition [46] and for energizing the primary coils to control the amount of power received by the secondary coil [47].

\section{System performance and technical challenges}

Table 1 summarizes the system parameters of selected stationary charging systems. The efficiency is high at the desirable output power levels, but note that the efficiency measurement is inconsistent in the literature. For different research purposes, some studies have AC grid to battery pack measurement, some have DC input to battery pack efficiency, and some report coil efficiency. From the system analysis and sustainability assessment perspectives, it is preferable to know the AC grid to battery pack efficiency as it provides comprehensive characterization of the charger performance and it is directly related to the overall energy consumption assessment and electricity cost calculation for the economic evaluation. It is recommended to consistently report AC grid to battery pack efficiency as a preferred common practice for efficiency measurement.

The sizes of both primary coils and secondary coils are larger than conductive chargers in most cases. Researchers from ETH Zurich developed a relatively compact wireless charging system and the power density is higher than any other system listed in Table 1. However, the system may be more sensitive to misalignment than other listed systems. There is a trade-off between compact and lightweight structure and good system performance [49], and balancing the size of the stationary charging system and its misalignment tolerance is an ongoing practical challenge for researchers.

Table 1. Summary of system parameters of selected stationary charging systems.

\begin{tabular}{|c|c|c|c|c|c|c|c|c|}
\hline Institute & $\begin{array}{l}\text { Power } \\
(k W)\end{array}$ & Efficiency & $\begin{array}{l}\text { Switching } \\
\text { frequency } \\
(\mathrm{Hz})\end{array}$ & $\begin{array}{l}\text { Air gap } \\
(\mathrm{mm})\end{array}$ & $\begin{array}{l}\text { Transmitter } \\
\text { size }\left(\mathrm{cm}^{2}\right)\end{array}$ & $\begin{array}{l}\text { Receiver } \\
\text { size } \\
\left(\mathrm{cm}^{2}\right)\end{array}$ & Year & References \\
\hline \multirow{3}{*}{ Univ. of Auckland } & 2 & & $20 \mathrm{k}$ & 200 & 3848 & 3848 & 2011 & {$[20]$} \\
\hline & $2-7$ & & $20 \mathrm{k}$ & $100-250$ & 3100 & 3100 & 2013 & {$[25]$} \\
\hline & 1 & $91.3 \%^{\mathrm{c}}$ & $85 \mathrm{k}$ & 100 & 1385 & 1385 & 2015 & {$[26]$} \\
\hline
\end{tabular}


Table 2. Summary of system parameters of selected dynamic charging systems.

\begin{tabular}{lllllllll}
\hline Institute & $\begin{array}{l}\text { Power } \\
(\mathrm{kW})\end{array}$ & Efficiency & $\begin{array}{l}\text { Switching } \\
\text { frequency } \\
(\mathrm{Hz})\end{array}$ & $\begin{array}{l}\text { Air gap } \\
(\mathrm{mm})\end{array}$ & $\begin{array}{l}\text { Transmitter } \\
\text { width }(\mathrm{cm})\end{array}$ & $\begin{array}{l}\text { Receiver } \\
\text { size }\left(\mathrm{cm}^{2}\right)\end{array}$ & Year & References \\
\hline KAIST & $3-25$ & $72 \%-83 \%^{\mathrm{a}}$ & $20 \mathrm{k}$ & $10-200$ & $10-140$ & $990-13600$ & 2009 & {$[7]$} \\
ORNL & 1.5 & $75 \%$ & $23 \mathrm{k}$ & 100 & 33 & 855 & 2013 & {$[6]$} \\
NCSU & 0.3 & $77.82 \%{ }^{\mathrm{b}}$ & $100 \mathrm{k}$ & 170 & 35 & 1225 & 2014 & {$[30]$} \\
\hline
\end{tabular}

Notes: ${ }^{a}$ AC grid to battery pack efficiency; ${ }^{b}$ DC input to battery pack efficiency. KAIST $=$ Korea Advanced Institute of Science and Technology; ORNL = Oak Ridge National Laboratory; NCSU = North Carolina State University.

The system performance of stationary and dynamic wireless chargers is fundamentally determined by the materials. Currently, copper is widely used as the coil material because of its good conductivity and relatively low price. Thin copper strands are twisted and woven together to make litz wires that are employed for winding coils, which not only minimizes the skin effects, but also gives enough current densities. $\mathrm{Mn}-\mathrm{Zn}$ ferrites are selected as the core materials to provide sufficient magnetic shielding at the desired frequencies. Aluminum is used for magnetic shielding because of its competitive performance and cost. With the advent of the new materials, such as high-temperature superconducting (HTS) materials and metamaterials, higher transfer efficiency and longer transmission distance can be achieved. Kim et al. [52] proposed a wireless 
showed that both the transfer efficiency and impedance matching were enhanced. Similarly, Chung et al. [53] built a wireless charging system with HTS transmitter coils and copper receiver coils. They proved that with the application of HTS materials, both the transfer efficiency and distance increased. Researchers from Mitsubishi Electric Research Laboratories analyzed the metamaterials, which had negative permeability. They demonstrated that the coupling effect between the two coils was able to be improved and the transfer efficiency was also further boosted with the use of a metamaterial slab [54]. Though their WPT system is not for EV applications, they provide potential possibilities for an EV wireless charging system to transfer power with higher efficiency and longer distance.

\section{Real-world applications and selected case studies}

\subsection{Public transit buses}

Because of the fixed-route attributes of urban transit bus systems, a significant portion of recent development and application of wireless charging has been focused on electric transit buses. A growing number of demonstrations on wireless charging electric bus systems have been reported, as highlighted in Table 3.

Table 3. Summary of selected wireless charging electric bus projects.

\begin{tabular}{|c|c|c|c|c|c|c|c|c|}
\hline Project & $\begin{array}{l}\text { Start } \\
\text { year }\end{array}$ & Location & Efficiency & $\begin{array}{l}\text { Frequency } \\
(\mathrm{Hz})\end{array}$ & $\begin{array}{l}\text { Power } \\
(k W)\end{array}$ & $\begin{array}{l}\text { Battery } \\
\text { capacity } \\
(k W h)\end{array}$ & $\begin{array}{l}\text { Air gap } \\
(\mathrm{mm})\end{array}$ & References \\
\hline Bus projects in Italy & 2003 & Turin, Italy & $90 \%^{b}$ & $15 \mathrm{k}-20 \mathrm{k}$ & 60 & & 40 & {$[55,56]$} \\
\hline $\begin{array}{c}\text { KAIST On-Line Electric } \\
\text { Vehicle (OLEV) }\end{array}$ & 2009 & South Korea & $72-83 \%{ }^{a}$ & $20 \mathrm{k}$ & $6-100$ & & $170-200$ & {$[7,57]$} \\
\hline $\begin{array}{l}\text { Bombardier PRIMOVE } \\
\text { IPT for Electric } \\
\text { Buses }\end{array}$ & 2010 & $\begin{array}{l}\text { Germany, } \\
\text { Belgium }\end{array}$ & $>90 \%{ }^{b}$ & $20 \mathrm{k}$ & $40-200$ & $36-90$ & & {$[7,58]$} \\
\hline $\begin{array}{l}\text { Chattanooga Area } \\
\text { Regional } \\
\text { Transportation } \\
\text { Authority (CARTA) }\end{array}$ & 2011 & $\begin{array}{l}\text { United States } \\
(\mathrm{TN})\end{array}$ & $90 \%^{a}$ & $15 \mathrm{k}-20 \mathrm{k}$ & 60 & & 40 & {$[55,59,60]$} \\
\hline $\begin{array}{l}\text { Wireless Advanced } \\
\text { Vehicle } \\
\text { Electrification } \\
\text { (WAVE) }\end{array}$ & 2012 & $\begin{array}{l}\text { United States } \\
\text { (UT, CA, TX, } \\
\text { MD) }\end{array}$ & $90 \%^{b}$ & 20k & $25-50$ & & $150-250$ & {$[55,61]$} \\
\hline $\begin{array}{l}\text { ZTE Corporation } \\
\text { projects }\end{array}$ & 2014 & $\begin{array}{l}\text { China (various } \\
\text { cities) }\end{array}$ & $90 \%^{a}$ & $45 \mathrm{k}$ & 30,60 & & 200 & {$[62-64]$} \\
\hline
\end{tabular}

Notes: ${ }^{a}$ AC grid to vehicle terminal efficiency; ${ }^{b}$ measurement terminals unknown.

Wireless charging can eliminate a major stumbling block for deploying urban electric transit buses - the range limitation. According to the Chattanooga Area Regional Transportation Authority (CARTA) project, a short "opportunity charge" of 1 minute at $60 \mathrm{~kW}$ can extend the range by approximately 1 mile $(\approx 1.61 \mathrm{~km})$ so that multiple charges in a day would release the 
range constraint to cover the required daily route of 100 miles $(\approx 161 \mathrm{~km})$, which otherwise requires battery swapping during the day [60].

Another obstacle for the expansion of traditional pure electric transit buses lies in the battery size, cost, and life. For a long-range all-electric bus, the battery pack can comprise about $26 \%$ of the weight and $39 \%$ of the total cost of the bus [10, 12, 65]. Among the various bus projects, the KAIST On-Line Electric Vehicle (OLEV) project in Korea has advanced technologies that allow buses to charge either while stationary or in motion to significantly downsize the battery. Beginning in 2009, the OLEV research group developed and applied the Shaped Magnetic Field in Resonance (SMFIR) technology in buses and a tram to demonstrate the dynamic wireless charging of EVs as a commercially viable approach [57]. The battery installed on a Gumi City bus is less than one-fifth the size of a normal conductively charged electric bus battery, which significantly reduces the procurement cost of OLEVs [11]. As a result of dynamic wireless charging, the state of charge (SOC) of an OLEV battery can be kept in a narrow 40\%-60\% SOC band that may help extend the battery life, instead of the large $20 \%-90 \%$ SOC swing of a normal conductively charged electric bus [66].

\subsection{Passenger cars}

As early as 2012, the U.S. Department of Transportation recognized the emergence of WPT for EV applications and identified the need to understand the implications of dynamic wireless charging of EVs on the U.S. highways [13]. In 2015, Utah State University built an advanced test facility for dynamic wireless charging [67]. Dynamic WPT may enable unlimited range extension for EVs [13]. EVs can run continuously without stopping in areas with available dynamic WPT infrastructure. Also, the battery capacity could be reduced to below $20 \%$ of a conventional EV battery [68].

Several feasibility studies were conducted to test the idea of deploying a dedicated WPT lane on major roadways for in-motion charging. ORNL partnered with three other U.S. Department of Energy laboratories and conducted a feasibility analysis of dynamic wireless charging using traffic data from Atlanta, GA [69]. The power requirement versus the vehicle speed profile was characterized using data from Argonne National Laboratory's chassis dynamometer testing facility and field tests of advanced vehicles at Idaho National Laboratory. A vehicle speed of 40 miles per hour $(\approx 64.37 \mathrm{~km} / \mathrm{h})$ was selected to meet the minimal speed requirements for operational status of typical commuter roadways, which corresponds to a power transfer level of $25 \mathrm{~kW}$. This power level is required to sustain vehicle travel and maintain the SOC. A higher power transfer level and relatively higher power from the vehicle propulsion system is required for greater speeds. The arterial routes that maximize roadway electrification return on investment were identified by using information from the National Renewables Energy Laboratory, by obtaining the most frequently traveled roadways based on vehicle miles traveled (VMT) and representative traffic volumes versus time of day. The $1 \%$ of arterial roads in Atlanta where $17 \%$ of VMT took place were selected as the most desirable road segments for charging. 
The infrastructure proposed to support this system was 12 transformers and inverters per mile (1 mile $\approx 1.61 \mathrm{~km}$ ) with a 100-meter maximum distance between inverter and coil [69]. In addition to research, ORNL is facilitating technology development and standards establishment by partnering with Evatran and Clemson University's International Center for Automotive Research (ICAR) to demonstrate ORNL WPT systems in fully operational original equipment manufacturer (OEM) vehicles in various applications in the spring of 2015 [69]. In Europe, another feasibility study being conducted with test sites in France, Italy, and Sweden is the feasibility analysis and development of on-road charging solutions for future electric vehicles (also called FABRIC). The project duration is from January 2014 to December 2017 with a total cost of 9 million Euros and it seeks to pave the way for large scale deployment of electromobility. It is supported and co-funded by the European Union in the Seventh Framework Programme for Research, Technological Development and Demonstration, European Council for Automotive R\&D (EUCAR) and ERTICO-ITS Europe [70].

\subsection{Other applications}

Wireless charging can also be applicable for other transportation modes that require continuous fixed-route operations, such as harbor, airport, rail systems, and theme parks. Transporting commodities from shipping ports to nearby distribution zones is often referred to as drayage operations. "Zero emission" drayage operations are the long term goal of many large port cities and wireless charging can help these vehicles operate continuously and enhance regional sustainable mobility in densely populated areas. The Port of Long Beach in Los Angeles, $\mathrm{CA}$ is identified as a candidate for such an implementation to combat the pollution and energy consumption related to the intense drayage operations [69].

\section{Sustainability, safety and social implications of WPT technology}

\subsection{Energy and environmental assessments}

Recent energy and environmental assessments have been focusing on the comparative analysis of wireless charging electric automobiles versus either conventional powertrain or plugin charging electric automobiles.

Wireless charging electric buses were found to have better performance than diesel buses in terms of carbon emissions. The CARTA project compared the use phase performance of a wireless charging electric bus to a diesel bus providing the same service. They reported an electric bus reduces $\mathrm{CO}_{2}$ emissions by approximately 38\% (equivalent to a reduction of 567 grams per mile), assuming fuel economies of 7 miles per gallon (mpg) for a diesel bus and 1.5 $\mathrm{kWh}$ per mile for an electric bus and emission factors of 10,274 grams of $\mathrm{CO}_{2}$ per gallon of diesel and 600 grams of $\mathrm{CO}_{2}$ per kWh of U.S. average electricity $(1$ mile $\approx 1.61 \mathrm{~km} ; 1$ gallon $\approx$ 3.785 liters) [60]. However, these results are use-phase only and lack the comprehensive perspective that a life cycle assessment also encompassing the burden of manufacturing, infrastructure deployment, and end-of-life would provide. 
Wireless charging electric buses were found to have comparable performance with plugin charging electric buses in terms of energy and greenhouse gas (GHG) emissions from a life cycle scope. The positive implication of wireless charging in terms of energy and environmental performance lies in the requirement of a downsized battery that significantly reduces vehicle weight and helps improve the fuel economy. The trade-off is the requirement of large-scale charging infrastructure deployment. In order to understand the energy and environmental tradeoffs of wireless charging technology, researchers at the University of Michigan conducted a life cycle analysis to compare plug-in versus stationary wireless charging technologies and illustrated the trade-off of the infrastructure burdens versus the battery-related savings by modeling an existing bus system in Ann Arbor, MI over a 12-year time frame [10]. Two main conclusions were drawn from this study: (1) Although there are additional energy and GHG emission burdens from the wireless charging infrastructure for transit buses, the benefits of battery downsizing can offset these burdens so that a wireless charging all-electric bus system would still be attractive in energy and environmental terms; (2) The bottleneck for further enhancing the sustainability of wireless charging mainly lies in the grid-to-battery charging efficiency. The wirelessly charged battery was shown to be $27 \%-44 \%$ the size of a plug-in charged battery. Although the associated reduction of $12 \%-16 \%$ in bus weight for the wireless buses can induce a reduction of $5.4 \%-7.0 \%$ in battery-to-wheel energy consumption, the relatively lower wireless charging efficiency could cancel out this lightweighting benefit from a primary energy perspective. As a result, a similar cumulative energy demand and global warming impact were obtained in the use phase for both charging technologies [10]. With the current technical maturity, the energy and environmental impact of wireless charging technology is similar to the plug-in charging technology from a life cycle perspective. However, further advances in charging efficiency and renewable energy penetration into the daytime or peak-hour electricity grid (provided that majority of wireless charging is during the daytime and the majority of plug-in charging is overnight) would enhance the sustainable performance of a wireless charging bus system [10].

Researchers at Utah State University [71] developed a model to evaluate the environmental impacts and techno-economic feasibility of dynamic WPT applied to interstate and urban roadways in the U.S., compared to conventional internal combustion engine vehicles (ICEVs). They reported that a light duty WPT EV has a $49 \% \mathrm{CO}_{2}$ reduction compared to a light duty ICEV as well as some reduction in the criteria pollutants, such as VOC, $\mathrm{CO}, \mathrm{NO}_{\mathrm{x}}, \mathrm{PM10}$, and PM2.5, except $\mathrm{SO}_{\mathrm{x}}$ [71]. An increase in $\mathrm{SO}_{\mathrm{x}}$ is primarily due to the dominance of coal, which was assumed to represent $39 \%$ of the U.S. power grid for the WPT EVs [71]. For both light duty vehicles and trucks in the U.S., a reduction of $10.1 \%$ in total $\mathrm{CO}_{2}$ emissions was reported assuming a $20 \%$ market penetration [71]. They also reported 2.6 years of societal payback time for the infrastructure at a $20 \%$ market penetration, resulting from the cost savings associated with the operation, maintenance, and purchase of the WPT vehicle architecture and roadway [71]. Although dynamic wireless charging electric automobiles showed good environmental performance compared to conventional powertrain vehicles, its environmental performance relative to the plug-in charging alternative is yet to be examined in the literature. 

adjacent coils is the key to analyzing the trade-off of infrastructure burden versus use phase performance. A coil pitch of $70 \%$ was used in the ORNL two-coil apparatus, resulting in a longitudinal gap between the adjacent coils. The power transfer minimum is $50 \%$ of full power when the receiver coil is midway between the transmitter coils [13]. Lower-density and separated power transfer pads would reduce material consumption and thus lower the infrastructure burdens, but it could result in a decrease of energy transmitted to the moving vehicle and pose large fluctuations on the grid attributable to the varying charging power demand [70]. Thus, an optimal coil pitch design is needed to minimize infrastructure burdens while still maintaining an acceptable level of power transfer.

Prospective energy and environmental assessments would need to incorporate the spatial and temporal heterogeneity of additional demand on the electricity grid from wireless charging EVs. For example, the power demand from in-motion WPT EV systems would be dynamic across both time and space [13]. There is an anticipated extra burden of energy supply on electricity load profiles as the demand from the dynamic WPT EVs is likely during peak hours of electricity consumption [13]. It would be useful for future work to compare the environmental assessment results between marginal and average grid emission intensities [72] to better understand the consequential/marginal environmental impacts of WPT EV adoption. Researchers have also proposed an optimization framework linking traffic assignment with power distribution in order to have a better understanding about transportation electrification and to answer these questions: (1) How many drivers are going to use the charging-in-motion services, in which locations, and at what time frame? (2) What level of power demand is expected in these locations, and what is the optimal operational plan for electric power distribution to respond to the demand? [73] Vehicle-to-grid (V2G) and grid-to-vehicle (G2V) communication and management should be another key aspect of prospective energy and environmental assessment of wireless charging technology. Instead of posing additional demand at peak load times, EVs have the potential for electricity load shifting, and their batteries provide storage for variable and transient energy sources, such as wind and solar power, that produce electricity in excess of current demand [68, 74]. In the future, EV recharging would be expected to interact with a smart grid in sophisticated and optimal management strategies, and more energy and environmental analyses would be required to investigate these impacts.

The continuous V2G and G2V communication and constant dynamic wireless charging on arterial roads would lead to a full vehicle autonomy and unconstrained range extension, at least where WPT infrastructure is deployed. Future environmental and energy assessment has to address the rebound effect brought by this emerging technology due to the convenience of wireless charging technology and reduced range anxiety [75], that is, the growth of environmental impacts due to the increase in VMT could offset the relative reduction of 
environmental impacts due to battery downsizing, vehicle lightweighting, and fuel economy improvement.

\subsection{Economic and policy analyses}

The economic competitiveness of wireless charging technology is influenced by three main components of the product life cycle: charging infrastructure; battery; and use phase energy costs. Compared to the wired charging hardware, the major difference with a wireless charger for a stationary WPT design is the two magnetic couplers which bring an extra material cost of about US\$400 for an $8 \mathrm{~kW}$ charger [68]. The cost increase for WPT charging hardware can be quite acceptable considering the convenience, battery downsizing, and long-term operation cost savings brought by wireless charging [55]. Wireless bus charging can reduce fuel costs by over $80 \%$ (US\$90,000) over the vehicle's life compared to a diesel bus [60]. For dynamic wireless charging on highways, it is noteworthy that the infrastructure investment would be cost effective given that the U.S. interstate highways make up only about $1 \%$ of roadway miles, yet they carry $22 \%$ of all miles traveled [76]. Meanwhile the utilization of the installed infrastructure can be high due to a large number of vehicles traveling on the same roadway segments [9]. Given more opportunity charges while driving, dynamic wireless charging can further mitigate the high purchase cost of EVs by allowing a substantially downsized onboard energy-storage system [9], which lightweights the vehicle and would further improve the overall energy and economic performance during operation [10,77]. Wireless charging electric buses were found to be more economically competitive than conventional diesel, diesel hybrid and plug-in charging electric buses in a life cycle scope [77], but the life cycle economic performance of dynamic wireless charging cars is not well established yet. Current available cost data for wireless charging obtained from the literature, government reports, and manufacturers are summarized in Table 4. 


\begin{tabular}{|c|c|c|c|c|c|c|c|}
\hline $\begin{array}{l}\text { Model or } \\
\text { real case }\end{array}$ & Cost scope & Mode & Vehicle & Location & Cost & Note & Source \\
\hline Model & Life cycle & Stationary & Bus & $\begin{array}{l}\text { Ann Arbor, } \\
\text { MI }\end{array}$ & $\$ 0.99 /$ bus-km & $\begin{array}{l}\text { Infrastructure }+ \text { use phase } \\
\text { also includes bus cost }\end{array}$ & {$[77]$} \\
\hline Model & $\begin{array}{l}\text { Infrastructure } \\
\text { only }\end{array}$ & Dynamic & Car & Atlanta, GA & $\begin{array}{l}\$ 2.8 \\
\text { million/lane-mile }\end{array}$ & $\begin{array}{l}\text { Hardware + deployment } \\
\text { including labor }\end{array}$ & [69] \\
\hline Model & $\begin{array}{l}\text { Infrastructure } \\
\text { only }\end{array}$ & Dynamic & Car & Atlanta, GA & $\begin{array}{l}\$ 350,000 / \text { lane- } \\
\text { mile }\end{array}$ & Grid connection cost only & [69] \\
\hline Model & $\begin{array}{l}\text { Infrastructure } \\
\text { only }\end{array}$ & Dynamic & $\begin{array}{l}\text { Car }+ \\
\text { Truck }\end{array}$ & United States & $\begin{array}{l}\$ 2.4 \\
\text { million/lane-mile }\end{array}$ & $\begin{array}{l}\text { WPT electronics }+ \\
\text { electric power delivery } \\
\text { infrastructure }\end{array}$ & {$[71]$} \\
\hline Real case & $\begin{array}{l}\text { Infrastructure } \\
\text { only }\end{array}$ & Dynamic & Bus & Korea & $\begin{array}{l}\$ 0.85-1.07 \\
\text { million } / \mathrm{km}\end{array}$ & $\begin{array}{l}\text { Electronic components } \\
\text { and construction for } \\
\text { two-way roads }\end{array}$ & {$[7]$} \\
\hline Real case & $\begin{array}{l}\text { Infrastructure } \\
\text { only }\end{array}$ & Dynamic & Bus & Korea & $\begin{array}{l}\$ 15,000 \text { (fixed) } \\
+\$ 200 / \mathrm{m} \\
\text { (variable) per } \\
\text { station }\end{array}$ & $\begin{array}{l}\text { Fixed cost mainly } \\
\text { includes the inverter } \\
\text { cost and the labor cost } \\
\text { to connect it to the } \\
\text { grid. The variable cost } \\
\text { depends on the length } \\
\text { of the power } \\
\text { transmitter. }\end{array}$ & {$[78]$} \\
\hline Real case & Charger only & Stationary & Car & Worldwide & $\begin{array}{l}\$ 1,940-\$ 2,440 \\
\text { per } 3.3 \mathrm{~kW} \\
\text { charger }\end{array}$ & $\begin{array}{l}\text { Wireless chargers sold by } \\
\text { Plugless Power }\end{array}$ & [79] \\
\hline Real case & $\begin{array}{l}\text { Use phase } \\
\text { only }\end{array}$ & Stationary & Bus & Italy & $\$ 9,000 /$ bus-year & Electricity cost & {$[55]$} \\
\hline Real case & $\begin{array}{l}\text { Use phase } \\
\text { only }\end{array}$ & Stationary & Bus & $\begin{array}{l}\text { Chattanooga, } \\
\text { TN }\end{array}$ & $<\$ 0.10 /$ bus-mile & Energy cost & {$[60]$} \\
\hline
\end{tabular}

Note: all currency is U.S. dollars; 1 mile $\approx 1.60934 \mathrm{~km}$.

A key issue in the economic analysis of wireless charging technology lies in the economic allocation of charging infrastructure and determination of battery capacity. More wireless charging stations deployed will lead to a requirement of a smaller onboard battery, and vice versa. Trade-off of these two design variables has been evaluated in several optimization studies to minimize the investment cost of a wireless charging bus route in Korea [78, 80, 81]. The cost function to be minimized consists of the battery cost and cost of the power transmitters. The power transmitter cost is made up of a fixed cost and a variable cost. Fixed cost mainly includes the inverter cost (one for each power transmitter) and the labor cost to connect it to the grid. The variable cost depends on the length of the power transmitter [78]. Further studies are needed to extend this optimization framework to a network of multiple bus routes with interconnected charging stations where the utilization of each charging station can be increased. The cost function would also need to be extended to include not only the capital cost but also the use phase cost (battery replacement, charger maintenance, and electricity costs). For highway dynamic wireless charging for passenger cars, a framework to optimize the distribution of charging infrastructure and battery capacity with the minimum life cycle cost is yet to be established. 
Road infrastructure improvements and increasing EV sales need to be coordinated by a portfolio of policy instruments to guide the proper deployment of wireless charging infrastructure. This massive transformation in personal and commercial electric mobility would require a focused long-term strategy and large scale infrastructure planning and deployment for targeted municipalities [69]. If WPT for EVs is demonstrated to enhance sustainable mobility, it would require government subsidies and incentives to enable penetration of this new and disruptive technology and guide the synergistic deployment of WPT technologies and the increasing penetration of EVs in the auto market [69]. In order to characterize the impact of advanced technologies on consumer behavior, ORNL developed the Market Acceptance of Advanced Automotive Technologies ( $\left.\mathrm{MA}^{3} \mathrm{~T}\right)$ model and predicted that dynamic wireless charging could boost the EV share of light duty vehicle (LDV) sales to more than $60 \%$ by 2050. In comparison, when there is no dynamic WPT system deployment throughout the timeline, the share can only reach $20-30 \%$ by 2050 [69, 82]. EV sales boosted by WPT technology would be of value for car manufacturers as it will be a technology multiplier to credit their fleet corporate average fuel economy (CAFE) figures in the 2025 calculations [69]. To guide policy makers on infrastructure deployment, researchers tested three vehicles (a compact car: Honda Insight, a large car: Chevrolet Impala, and an SUV: Ford Explorer) to find out the infrastructure coverage required for 300 mile $(\approx 482.8 \mathrm{~km})$ range $(30 \mathrm{~kW}$ delivered to the vehicle). They found that a coverage of $0.46 \%$ - $1 \%$ of lane-miles is required for UDDS city drive cycle, a $17 \%-43.8 \%$ coverage is required for HWFET highway drive cycle, and a $17.2 \%-64.3 \%$ coverage is required for HW-MTN (highway driving in a mountainous region) drive cycle $[9,83]$. They concluded that if only $1 \%$ of the roadway is powered in urban areas, most vehicle types can easily reach the 300 -mile target range with a relatively small battery pack $[9,83]$.

\subsection{Health and safety}

Although the road-embedded WPT technologies would improve system operational safety (since there are no exposed high voltage cables or power outlets as plug-in vehicles) [55], significant research has been conducted $[6,21,84,85]$ to investigate the EMF issues with human electromagnetic exposure limits. Well-defined biological responses caused by exposure to electric and magnetic fields below $100 \mathrm{kHz}$ include annoyance, surface electric-charge effects, the stimulation of central and peripheral nervous tissues, and the induction in the retina of phosphenes (a perception of faint flickering light in the periphery of the visual field) [86]. The EMF may also induce high field strengths and heating in nearby human bodies, implanted medical devices, small animals, and metals. The two most prevailing exposure limits are those published by the Institute for Electrical and Electronic Engineers (IEEE) and the International Commission on Non-Ionizing Radiation Protection (ICNIRP) [59]. For example, ICNIRP [86] sets limitations on both electric fields and magnetic fields. For electric fields, a human body is a good conductor. The external electric field will induce an electric field inside the human body. ICNIRP has a limit on the internal electric fields of all human tissues, which cannot exceed $1.35 \times 10^{-4}$ times the frequency value. Furthermore, ICNIRP has a limit on general public exposure to electric fields, which is set to be $83 \mathrm{~V} / \mathrm{m}$. For magnetic fields, the tissue has the same 
permeability as air. The tissue has the same magnetic flux density with that of the external field. ICNIRP has a limit on general public exposure to magnetic fields, which is updated as $27 \mu \mathrm{T}$ in 2010. Additionally, $6.25 \mu \mathrm{T}$, which was the limit set in 1998, is still commonly used in recent experiments.

Current research found that EMF can be effectively controlled within acceptable levels, but further research is still required to ensure health and safety under variable conditions and as the technology evolves. For transit buses, researchers characterized potential exposure of people to the fields associated with a wireless charging electric bus operated by CARTA in Tennessee. They found that during charging none of the magnetic or electric fields measured either inside or outside the bus exceeded the IEEE or the ICNIRP limits for the general public [59]. Researchers can effectively shield the EMF from affecting passengers onboard by utilizing aluminum plates at the back of the secondary pad to protect the interior of the vehicle and aluminum rings at both the primary and secondary pads to limit the stray field in the lateral direction $[9,55]$. The eddy currents generated when the magnetic flux passes through the aluminum shield will induce a new magnetic flux that is in the opposite direction of the original magnetic flux, resulting in an effect of shielding the original magnetic flux. For dynamic wireless charging of in-motion passenger cars, researchers at ORNL [6] controlled the EMF at $23 \mathrm{kHz}$ within the acceptable standards for the general public of $6.25 \mu \mathrm{T}$ set by the ICNIRP by utilizing aluminum shielding. Further research, however, is still required to ensure health and safety of dynamic charging under open traffic environments that have more unforeseeable conditions than for lab test environments, such as variable power levels required for light-duty and heavy-duty vehicles under varying speeds and accidental leakage exposure to nearby passing pedestrians, cyclers, and patients with implanted medical devices. Living object detection systems and foreign object detection systems are required for detecting subjects and metals nearby.

\subsection{Prospects to enhance sustainable mobility}

Challenges and opportunities coexist in the near-term and long-term development of WPT technology for sustainable transportation. A series of technical and sustainability challenges and opportunities are identified in Table 5. 
Table 5. Prospects to enhance sustainable mobility - coexistence of challenges and opportunities of WPT technology.

\begin{tabular}{|c|c|c|}
\hline & Short description & Detailed description \\
\hline \multirow{8}{*}{$\begin{array}{l}\text { Challenges } \\
{[13,31,70]}\end{array}$} & $\begin{array}{l}\text { Maintenance of dynamic } \\
\text { alignment }\end{array}$ & $\begin{array}{l}\text { Lateral alignment for lane keeping and optimal power transfer } \\
\text { coupling for dynamic charging }\end{array}$ \\
\hline & $\begin{array}{c}\text { Charger life and } \\
\text { durability }\end{array}$ & $\begin{array}{c}\text { Need to remain in the road without degrading the structure for at least } \\
20 \text { years and cope with resurfacing works every } 10-12 \text { years }\end{array}$ \\
\hline & $\begin{array}{r}\text { Utility power } \\
\text { distribution }\end{array}$ & $\begin{array}{l}\text { Connect and distribute the power supply to the point of charging } \\
\text { event }\end{array}$ \\
\hline & $\begin{array}{l}\text { Burden on electricity } \\
\text { grid }\end{array}$ & Multiple vehicles on charging lane and power flow management \\
\hline & $\begin{array}{r}\text { Synchronization of } \\
\text { energizing coils }\end{array}$ & $\begin{array}{l}\text { Low-latency private and secure vehicle-to-infrastructure } \\
\text { communications for roadway coil excitation sequencing }\end{array}$ \\
\hline & Economic management & Time of use and revenue structure \\
\hline & Health and safety & $\begin{array}{l}\text { Leakage fields: the magnetic and electric fringe fields associated with } \\
\text { high frequency magnetic resonance power transfer }\end{array}$ \\
\hline & $\begin{array}{c}\text { Tolerance for diverse } \\
\text { power demands }\end{array}$ & $\begin{array}{l}\text { Acceptable power levels versus different vehicle class types (car, } \\
\text { truck, and bus, etc.) }\end{array}$ \\
\hline \multirow{5}{*}{ Opportunities } & New materials & $\begin{array}{l}\text { With the advent of the new materials, such as high-temperature } \\
\text { superconducting (HTS) materials and metamaterials, higher } \\
\text { transfer efficiency can be achieved [52-54] }\end{array}$ \\
\hline & $\begin{array}{l}\text { Dynamic charging: } \\
\text { range extension }\end{array}$ & $\begin{array}{l}\text { Depending on the power capability, the use of dynamic charging } \\
\text { would further increase driving range and reduce the size of the } \\
\text { battery pack [9] }\end{array}$ \\
\hline & $\begin{array}{l}\text { Coupling with } \\
\text { automated vehicles } \\
\text { (AVs) }\end{array}$ & $\begin{array}{l}\text { AVs would accelerate the adoption for WPT technology by } \\
\text { leveraging capabilities such as charging alignment precision by } \\
\text { lane-following technologies to keep proper alignment between } \\
\text { the vehicle and the grid power supply units and improve the } \\
\text { driving performance and energy efficiency [69] }\end{array}$ \\
\hline & Vehicle connectivity & $\begin{array}{l}\text { Vehicle connectivity and communication will be required for proper } \\
\text { system effectiveness: both with the grid and other vehicles as } \\
\text { well as vehicle speed control [69] }\end{array}$ \\
\hline & $\begin{array}{l}\text { Automated highway } \\
\text { system (AHS) }\end{array}$ & $\begin{array}{l}\text { This concept called for continued personal ownership of the vehicle, } \\
\text { but capable of commuting on traditional highways and streets in } \\
\text { addition to a higher speed operation on an automated guideway. } \\
\text { The highway carrying capacity could be dramatically increased } \\
\text { to more than } 2500 \text { vehicle/hour/lane and remain environmentally } \\
\text { sustainable [13] }\end{array}$ \\
\hline
\end{tabular}

\section{Conclusions}

This paper contains a review of the status of WPT development and applications in the transportation sector. The challenges and opportunities in terms of technology and sustainability performance have been enumerated and discussed.

The first section was a review of the technical aspects of both stationary and dynamic charging systems in three areas: (1) coil design; (2) compensation topologies; and (3) power electronics converters and control methods. Progress in technology has led to improved system 
performance. Stationary wireless charging systems have comparable system performance to conductive charging systems, and dynamic wireless charging systems are on the path to achieve the charging of vehicles in motion. From the technical perspective, major research gaps are: (1) how to improve the system efficiency of dynamic charging systems and maximize the amount of energy received by vehicles at high speed in a limited charging lane range; and (2) how to balance the size of the charging system and its misalignment tolerance and efficiency.

From the sustainability perspective, WPT EVs have the trade-off of large infrastructure deployment versus the benefits of battery downsizing and vehicle lightweighting. WPT technology offers the possibilities for better energy performance, lower environmental impacts, lower life cycle cost, and more convenience and operational safety benefits compared to wired EVs and conventional ICEVs. In order to realize these possibilities of WPT EVs, the following research gaps need to be filled: (1) electricity grid management that balances the demand and supply of electricity for both static and moving vehicles; (2) optimization of large scale charging infrastructure deployment and battery capacity with a consideration of battery life for both public transit and passenger car applications; and (3) policies that coordinate the growth and development of WPT technology with other emerging EV technologies, such as connected and automated vehicles (CAVs).

Challenges and opportunities remain in the design and deployment of WPT EV systems. Dynamic wireless charging offers opportunities for sustaining the battery charge while driving so that the large battery pack that represents a bottleneck for deploying EVs can be eliminated and range anxiety will be reduced. The environmental, economic and societal impacts of large scale infrastructure deployment and performance in terms of energy efficiency, durability, and reliability must be carefully evaluated for prospective real-world deployment of dynamic WPT EVs. Stationary WPT for residential and commercial charging is expected to have earlier wide spread adoption than dynamic charging given its technical maturity and economic feasibility, while dynamic WPT could be implemented gradually if the market develops enough to significantly lower the high initial infrastructure cost. Connected and automated vehicles (CAVs) would provide strong synergy and accelerate the adoption of WPT technology by leveraging capabilities (such as charging alignment precision) to improve driving performance and energy efficiency. WPT technology also offers more active connectivity with the electric grid through V2G and G2V bidirectional power transfer, enabling EVs to become mobile energy storage devices to help regulate the grid by storing excess generation from uncontrolled renewables. In the next decade, improvements of WPT in these areas will determine how significant the role of WPT technology will be in advancing vehicle electrification and improving the sustainability of electrified mobility.

\section{Acknowledgements}




\section{References}

[1] Tesla N. Art of transmitting electrical energy through the natural mediums. U.S. Patent 787412; April $18,1905$.

[2] Tesla N. Apparatus for transmitting electrical energy. U.S. Patent 1119732; December 1, 1914.

[3] Zhang Y, Zhao Z, Chen K. Frequency-splitting analysis of four-coil resonant wireless power transfer. IEEE Trans Ind Appl 2014;50(4):2436-45.

[4] Zhang W, White JC, Abraham AM, Mi CC. Loosely coupled transformer structure and interoperability study for EV wireless charging systems. IEEE Trans Power Electron 2015;30(11):6356-67.

[5] Nguyen TD, Li S, Li W, Mi CC. Feasibility study on bipolar pads for efficient wireless power chargers. In: 2014 twenty-ninth annual IEEE applied power electronics conference and exposition (APEC), 16-20 March. IEEE; 2014. p. 1676-82.

[6] Onar OC, Miller JM, Campbell SL, Coomer C, White CP, Seiber LE. A novel wireless power transfer for in-motion EV/PHEV charging. In: 2013 twenty-eighth annual IEEE applied power electronics conference and exposition (APEC). IEEE; 2013. p. 3073-80.

[7] Choi SY, Gu BW, Jeong SY, Rim CT. Advances in wireless power transfer systems for roadwaypowered electric vehicles. IEEE J Emerg Sel Topics Power Electron 2015;3(1):18-36.

[8] Kurs A, Karalis A, Moffatt R, Joannopoulos JD, Fisher P, Soljačić M. Wireless power transfer via strongly coupled magnetic resonances. Science 2007;317(5834):83-6.

[9] Lukic S, Pantic Z. Cutting the cord: Static and dynamic inductive wireless charging of electric vehicles. IEEE Electrification Magazine: IEEE; 2013. p. 57-64.

[10] Bi Z, Song L, De Kleine R, Mi C, Keoleian GA. Plug-in vs. wireless charging: Life cycle energy and greenhouse gas emissions for an electric bus system. Appl Energy 2015;146:11-9.

[11] Thornton J. Pulling power from the road: Charged by the route it follows, an electric bus gets a real world test. Mechanical Engineering: ASME; 2014. p. 44-9.

[12] Reikes J at BYD Motors Inc., Personal communication; July 21, 2014.

[13] Miller JM, Jones PT, Li J-M, Onar OC. ORNL experience and challenges facing dynamic wireless power charging of EV's. IEEE Circuits and Systems Magazine: IEEE; 2015. p. 40-53.

[14] Musavi F, Eberle W, Dunford WG. A high-performance single-phase bridgeless interleaved PFC converter for plug-in hybrid electric vehicle battery chargers. IEEE Trans Ind Appl 2011;47(4):183343.

[15] Zhu Q, Wang L, Liao C. Compensate capacitor optimization for kilowatt-level magnetically resonant wireless charging system. IEEE Trans Ind Electron 2014;61(12):6758-68.

[16] Zhu Q, Guo Y, Wang L, Liao C, Li F. Improving the misalignment tolerance of wireless charging system by optimizing the compensate capacitor. IEEE Trans Ind Electron 2015;62(8):4832-6. 
[17] Bloom MA, Niu G, Krishnamurthy M. Design considerations for wireless electric vehicle charging. In: 2013 IEEE transportation electrification conference and expo (ITEC). IEEE; 2013. p. 1-6.

[18] Hui SYR, Zhong W, Lee CK. A critical review of recent progress in mid-range wireless power transfer. IEEE Trans Power Electron 2014;29(9):4500-11.

[19] Covic GA, Boys JT. Inductive power transfer. Proc IEEE 2013;101(6):1276-89.

[20] Budhia M, Covic GA, Boys JT. Design and optimization of circular magnetic structures for lumped inductive power transfer systems. IEEE Trans Power Electron 2011;26(11):3096-108.

[21] Wu HH, Gilchrist A, Sealy KD, Bronson D. A high efficiency $5 \mathrm{~kW}$ inductive charger for EVs using dual side control. IEEE Trans Ind Informat 2012;8(3):585-95.

[22] Budhia M, Covic G, Boys J. A new IPT magnetic coupler for electric vehicle charging systems. In: IECON 2010 - 36th annual conference on IEEE industrial electronics society. IEEE; 2010. p. 2487-92.

[23] Takanashi H, Sato Y, Kaneko Y, Abe S, Yasuda T. A large air gap $3 \mathrm{~kW}$ wireless power transfer system for electric vehicles. In: 2012 IEEE energy conversion congress and exposition (ECCE). IEEE; 2012. p. 269-74.

[24] Park C, Lee S, Cho G-H, Rim CT. Innovative 5-m-off-distance inductive power transfer systems with optimally shaped dipole coils. IEEE Trans Power Electron 2015;30(2):817-27.

[25] Budhia M, Boys JT, Covic GA, Huang CY. Development of a single-sided flux magnetic coupler for electric vehicle IPT charging systems. IEEE Trans Ind Electron 2013;60(1):318-28.

[26] Kamineni A, Covic GA, Boys JT. Analysis of coplanar intermediate coil structures in inductive power transfer systems. IEEE Trans Power Electron 2015;30(11):6141-54.

[27] Kissin MLG, Covic GA, Boys JT. Steady-state flat-pickup loading effects in polyphase inductive power transfer systems. IEEE Trans Ind Electron 2011;58(6):2274-82.

[28] Choi S, Huh J, Lee WY, Lee SW, Rim CT. New cross-segmented power supply rails for roadwaypowered electric vehicles. IEEE Trans Power Electron 2013;28(12):5832-41.

[29] Choi SY, Jeong SY, Gu BW, Lim GC, Rim CT. Ultraslim S-type power supply rails for roadwaypowered electric vehicles. IEEE Trans Power Electron 2015;30(11):6456-68.

[30] Lee K, Pantic Z, Lukic SM. Reflexive field containment in dynamic inductive power transfer systems. IEEE Trans Power Electron 2014;29(9):4592-602.

[31] Miller JM, Onar OC, White C, Campbell S, Coomer C, Seiber L, et al. Demonstrating dynamic wireless charging of an electric vehicle: The benefit of electrochemical capacitor smoothing. IEEE Power Electronics Magazine: IEEE; 2014. p. 12-24.

[32] Zhang W, Mi CC. Compensation topologies of high-power wireless power transfer systems. IEEE Trans Veh Technol 2015;PP(99):1-10.

[33] Wang C-S, Covic GA, Stielau OH. Power transfer capability and bifurcation phenomena of loosely coupled inductive power transfer systems. IEEE Trans Ind Electron 2004;51(1):148-57.

[34] Khaligh A, Dusmez S. Comprehensive topological analysis of conductive and inductive charging solutions for plug-in electric vehicles. IEEE Trans Veh Technol 2012;61(8):3475-89.

[35] Villa JL, Sallán J, Sanz Osorio JF, Llombart A. High-misalignment tolerant compensation topology for ICPT systems. IEEE Trans Ind Electron 2012;59(2):945-51.

[36] Sallán J, Villa JL, Llombart A, Sanz JF. Optimal design of ICPT systems applied to electric vehicle battery charge. IEEE Trans Ind Electron 2009;56(6):2140-9.

[37] Li S, Li W, Deng J, Nguyen TD, Mi CC. A double-sided LCC compensation network and its tuning method for wireless power transfer. IEEE Trans Veh Technol 2015;64(6):2261-73.

[38] Li W, Zhao H, Li S, Deng J, Kan T, Mi CC. Integrated LCC compensation topology for wireless charger in electric and plug-in electric vehicles. IEEE Trans Ind Electron 2015;62(7):4215-25.

[39] Deng J, Li W, Nguyen TD, Li S, Mi C. Compact and efficient bipolar coupler for wireless power chargers: Design and analysis. IEEE Trans Power Electron 2015;30(11):6130-40.

[40] Kan T, Nguyen T-D, White JC, Malhan RK, Mi C. A new integration method for an electric vehicle wireless charging system using LCC compensation topology: Analysis and design. IEEE Trans Power Electron 2016;PP(99):1-12. 
[41] Lu F, Zhang H, Hofmann H, Mi C. A high efficiency $3.3 \mathrm{~kW}$ loosely-coupled wireless power transfer system without magnetic material. In: 2015 IEEE energy conversion congress and exposition (ECCE). IEEE; 2015. p. 2282-6.

[42] Zahid ZU, Dalala ZM, Zheng C, Chen R, Faraci WE, Lai J-S, et al. Modeling and control of seriesseries compensated inductive power transfer system. IEEE J Emerg Sel Topics Power Electron 2015;3(1):111-23.

[43] Colak K, Asa E, Bojarski M, Czarkowski D, Onar OC. A novel phase-shift control of semibridgeless active rectifier for wireless power transfer. IEEE Trans Power Electron 2015;30(11):6288-97.

[44] Madawala UK, Neath M, Thrimawithana DJ. A power-frequency controller for bidirectional inductive power transfer systems. IEEE Trans Ind Electron 2013;60(1):310-7.

[45] Lee J-Y, Han B-M. A bidirectional wireless power transfer EV charger using self-resonant PWM. IEEE Trans Power Electron 2015;30(4):1784-7.

[46] Hao H, Covic GA, Boys JT. An approximate dynamic model of LCL-T-based inductive power transfer power supplies. IEEE Trans Power Electron 2014;29(10):5554-67.

[47] Hasan N, Wang H, Saha T, Pantic Z. A novel position sensorless power transfer control of lumped coil-based in-motion wireless power transfer systems. In: 2015 IEEE energy conversion congress and exposition (ECCE). IEEE; 2015. p. 586-93.

[48] Nguyen BX, Vilathgamuwa DM, Foo GHB, Wang P, Ong A, Madawala UK, et al. An efficiency optimization scheme for bidirectional inductive power transfer systems. IEEE Trans Power Electron 2015;30(11):6310-9.

[49] Covic GA, Boys JT. Modern trends in inductive power transfer for transportation applications. IEEE J Emerg Sel Topics Power Electron 2013;1(1):28-41.

[50] Choi SY, Huh J, Lee WY, Rim CT. Asymmetric coil sets for wireless stationary EV chargers with large lateral tolerance by dominant field analysis. IEEE Trans Power Electron 2014;29(12):6406-20.

[51] Bosshard R, Kolar JW, Mühlethaler J, Stevanovic I, Wunsch B, Canales F. Modeling and $\eta-\alpha-P a r e t o$ optimization of inductive power transfer coils for electric vehicles. IEEE J Emerg Sel Topics Power Electron 2015;3(1):50-64.

[52] Kim DW, Chung YD, Kang HK, Yoon YS, Ko TK. Characteristics of contactless power transfer for HTS coil based on electromagnetic resonance coupling. IEEE Trans Appl Supercond 2012;22(3):1-4.

[53] Chung YD, Lee CY, Kang HK, Park YG. Design consideration and efficiency comparison of wireless power transfer with HTS and cooled copper antennas for electric vehicle. IEEE Trans Appl Supercond 2015;25(3):1-5.

[54] Wang B, Yerazunis W, Teo KH. Wireless power transfer: Metamaterials and array of coupled resonators. Proc IEEE 2013;101(6):1359-68.

[55] Brecher A, Arthur D. Review and evaluation of wireless power transfer (WPT) for electric transit applications. Washington, DC: U. S. Department of Transportation; 2014.

[56] Conductix-Wampfler. Product overview: Inductive power transfer - IPT. Omaha, NE: ConductixWampfler; 2012.

[57] Suh IS, Kim J. Electric vehicle on-road dynamic charging system with wireless power transfer technology. In: 2013 IEEE international electric machines \& drives conference (IEMDC), 12-15 May. IEEE; 2013. p. 234-40.

[58] Bombardier PRIMOVE team. Projects of Bombardier PRIMOVE, http://primove.bombardier.com/; 2015 [accessed June 2015].

[59] Tell RA, Kavet R, Bailey JR, Halliwell J. Very-low-frequency and low-frequency electric and magnetic fields associated with electric shuttle bus wireless charging. Radiat Prot Dosim 2014;158(2):123-34.

[60] Bailey JR, Hairr ME. Wayside charging and hydrogen hybrid bus: Extending the range of electric shuttle buses. Washington, DC: U.S. Department of Transportation Federal Transit Administration; 2012.

[61] WAVE team. WAVE Projects, http://www.waveipt.com/; 2015 [accessed June 2015]. 
[62] ZTE Corporation. Launch of the first pre-commercial bus route in China deploying buses with highpower wireless-charging system, http://wwwen.zte.com.cn/en/about/investor_relations/announcement/201409/P020140918693716018 772.pdf; 2014 [accessed November 2015].

[63] ZTE Corporation. ZTE innovative auto wireless charging solution, https://www.itu.int/en/ITUT/extcoop/cits/Documents/ITS\%20Events-201507-Beijing/Presentations/S1P4-Academus-Tian.pdf; 2015 [accessed November 2015].

[64] ZTE Corporation. Leading industrial solution and commercial implementation case study in China, http://www.apec-conf.org/wp-content/uploads/IS-12.4.pdf; 2015 [accessed November 2015].

[65] BYD Auto Company. 2013 BYD 40-ft electric bus specs, http://www.byd.com/la/auto/ebus.html; 2013 [accessed May 2014].

[66] Suh IS, Gu Y. Application of shaped magnetic field in resonance (SMFIR) technology to future urban transportation. In: CIRP design conference 2011. 2011. p. 226-32.

[67] Morris C. The dynamic road ahead: Utah State University builds the nation's most advanced test facility for dynamic wireless charging. Charged EVs: chargedevs.com; Nov/Dec 2014. p. 82-7.

[68] Li S, Mi C. Wireless power transfer for electric vehicle applications. IEEE J Emerg Sel Topics Power Electron 2014;3(1):4-17.

[69] Jones PT, Onar O. Impact of wireless power transfer in transportation: Future transportation enabler, or near term distraction. In: 2014 IEEE international electric vehicle conference (IEVC). IEEE; 2014. p. $1-7$.

[70] Naberezhnykh D. Feasibility analysis and development of on-road charging solutions for future electric vehicles: Dynamic Wireless Power Transfer, http://www.fabricproject.eu/images/Presentations/CERV 2015 - Denis Naberezhnykh - FABRIC - V1.pdf; 2015 [accessed June 2015].

[71] Quinn JC, Limb BJ, Pantic Z, Barr P, Zane R. Techno-economic feasibly and environmental impact of wireless power transfer roadway electrification. In: 2015 IEEE wireless power transfer conference (WPTC). IEEE; 2015. p. 1-3.

[72] Zivin JSG, Kotchen MJ, Mansur ET. Spatial and temporal heterogeneity of marginal emissions: Implications for electric cars and other electricity-shifting policies. J Econ Behav Organ 2014;107:248-68.

[73] Li J-M, Jones PT, Onar O, Starke M. Coupling electric vehicles and power grid through charging-inmotion and connected vehicle technology. In: 2014 IEEE international electric vehicle conference (IEVC). IEEE; 2014. p. 1-7.

[74] Huang X, Qiang H, Huang Z, Sun Y, Li J. The interaction research of smart grid and EV based wireless charging. In: 2013 IEEE vehicle power and propulsion conference (VPPC). IEEE; 2013. p. $1-5$.

[75] Miller SA, Keoleian GA. Framework for analyzing transformative technologies in life cycle assessment. Environ Sci Technol 2015;49(5):3067-75.

[76] Wu HH, Gilchrist A, Sealy K, Israelsen P, Muhs J. A review on inductive charging for electric vehicles. In: 2011 IEEE international electric machines \& drives conference (IEMDC), 15-18 May. IEEE; 2011. p. 143-7.

[77] Bi Z, De Kleine R, Keoleian GA. Integrated life cycle assessment and life cycle cost model for comparing plug-in versus wireless charging for an electric bus system. J Ind Ecology 2016; In Press.

[78] Jang YJ, Suh ES, Kim JW. System architecture and mathematical models of electric transit bus system utilizing wireless power transfer technology. IEEE Syst J 2015;PP(99):1-12.

[79] Plugless Power. Plugless Power website, https://www.pluglesspower.com/; 2015 [accessed June 2015].

[80] Jeong S, Jang YJ, Kum D. Economic analysis of the dynamic charging electric vehicle. IEEE Trans Power Electron 2015;30(11):6368-77.

[81] Ko YD, Jang YJ. The optimal system design of the online electric vehicle utilizing wireless power transmission technology. IEEE Trans Intell Transp Syst 2013;14(3):1255-65. 
[82] Lin Z, Li J, Dong J. Dynamic wireless power transfer: Potential impact on plug-in electric vehicle adoption. SAE Technical Paper 2014-01-1965; 2014.

[83] Pantic Z, Bai S, Lukic SM. Inductively coupled power transfer for continuously powered electric vehicles. In: IEEE vehicle power and propulsion conference (VPPC). IEEE; 2009. p. 1271-8.

[84] Christ A, Douglas MG, Roman JM, Cooper EB, Sample AP, Waters BH, et al. Evaluation of wireless resonant power transfer systems with human electromagnetic exposure limits. IEEE Trans Electromagn Compat 2013;55(2):265-74.

[85] Ding P-P, Bernard L, Pichon L, Razek A. Evaluation of electromagnetic fields in human body exposed to wireless inductive charging system. IEEE Trans Magn 2014;50(2):1037-40.

[86] International Commission on Non-Ionizing Radiation Protection. Guidelines for limiting exposure to time-varying electric and magnatic fields (1 Hz - $100 \mathrm{kHz}$ ). Health Phys 2010;99(6):818-36. 